\title{
Fontes orais e sua relevância documental para as narrativas de memória nas organizações
}

\author{
Oral sources and their documentary relevance for memory narratives in organizations
}

\author{
Vanderléa Nobrega de Azevedo Cortes \\ Mestra em Gestão da Informação e do Conhecimento pelo Programa de Pós-Graduação em Gestão da \\ Informação e do Conhecimento da Universidade Federal de Sergipe - UFS, Brasil. \\ Professora Tutora do Curso de Biblioteconomia em EAD pela Universidade Federal de Sergipe - UFS. \\ E-mail: vanderleanobregaacortes@gmail.com \\ Valéria Aparecida Bari \\ Doutora em Ciência da Informação pela Universidade de São Paulo - USP, Brasil. \\ Professora Associado da Universidade Federal de Sergipe - UFS, Brasil \\ E-mail: valbari@gmail.com
}

Cleide Aparecida Freires Belchior

Mestranda do Programa de Pós-Graduação em Gestão da Informação e do Conhecimento no Mestrado Profissional em Gestão da Informação e do Conhecimento pela Universidade Federal de Sergipe - UFS, Brasil. Assistente Técnica da Coordenação do Patrimônio e Meio Ambiente da Advocacia-Geral da União, Procuradoria da União no Estado de Sergipe, Brasil. E-mail: cleidefreiresbelchior@gmail.com

\section{Resumo}

Dialogando com a evolução da Ciência da Informação (CI) e suas relações histórico-sociais entre Biblioteconomia e Documentação, que tem sido amplamente explorada sem delimitar fronteiras do saber e campo de atuação dos profissionais da área, este artigo envolve considerações que se entrelaçam entre as fontes orais e sua relevância documental para as narrativas de memória no âmbito das organizações. Através de uma pesquisa de revisão narrativa de literatura, teve por objetivo identificar como as fontes orais podem preencher as lacunas documentais no âmbito das organizações através das narrativas de memória. Compõe um cenário de discussões contemporâneas embasado por um referencial teórico que destaca a gestão documental e suas possibilidades de reconhecer as fontes orais como fonte documental de recuperação da informação. Aborda a relação do arquivo e da gestão documental expandindo as bases teóricas por diversos autores que permeiam pela interdisciplinaridade dos conceitos da memória, destacando autores clássicos como Jacques Le Gof (1990), Maurice Halbwachs (1990) e Pierre Nora (1993), aproximando-os aos diálogos contemporâneos que exploram as narrativas de memória como estratégia de comunicação e da memória organizacional, a saber: Icleía Thiessen (2013), Karen Worcman (2004) e Rodrigo Cogo (2016) vinculando ainda a relação indissociável dos arquivos com a memória defendida por Almeida (2017), Barros e Amélia (2009). Destaca o poder da informação face as mudanças tecnológicas da sociedade do conhecimento que através dos documentos, monumentos e na oralidade supera a objetividade dos fatos e conclui que as fontes orais compõem parte essencial para preencher as lacunas documentais existentes, acrescentando que a estruturação da memória organizacional promove a compreensão do presente como elemento norteador para o futuro da organização, sendo importante destacar que a memória organizacional é a amplitude de documentos, monumentos e oralidade.

Palavras-Chave: Fontes orais. Memória. Gestão Documental. Gestão do Conhecimento. 


\begin{abstract}
Dialogging with the evolution of Information Science (CI) and its historical-social relations between Librarianship and Documentation, which has been widely explored without delimiting the boundaries of knowledge and field of action of professionals in the area, this article involves considerations that are intertwined between oral sources and their documentary relevance to memory narratives within organizations. Through a research of narrative literature review, the objective was to identify how oral sources can fill documentary gaps within organizations through memory narratives. It composes a scenario of contemporary discussions based on a theoretical framework that highlights document management and its possibilities to recognize oral sources as a documentary source of information retrieval. It addresses the relationship between archive and document management, expanding the theoretical bases by several authors that permeate the interdisciplinarity of the concepts of memory, highlighting classic authors such as Jacques Le Gof (1990), Maurice Halbwachs (1990) and Pierre Nora (1993), approaching those to contemporary dialogues that explore memory narratives as a communication strategy and organizational memory, namely: Icleía Thiessen (2013), Karen Worcman (2004) and Rodrigo Cogo (2016) linking the inseparable relationship of archives with the defended memory by Almeida (2017), Barros and Amélia (2009). It highlights the power of information in the face of technological changes in the knowledge society that, through documents, monuments and orally, overcomes the objectivity of facts and concludes that oral sources form an essential part to fill the existing documentary gaps, adding that the structuring of organizational memory promotes the understanding of the present as a guiding element for the future of the organization, it is important to highlight that organizational memory is the breadth of documents, monuments and orality.
\end{abstract}

Keywords: Oral sources. Memory. Document management. Knowledge management.

\title{
1. Introdução
}

No ambiente organizacional, questões documentais representam muito mais que os arquivos tradicionais de suporte físico, digital ou híbrido, porque envolvem uma nova cultura informacional que detém também, na oralidade dos integrantes da organização, o conhecimento tácito, que junto ao conhecimento explícito traduzem as experiências e contribuem com a aprendizagem e o conhecimento organizacional.

$\mathrm{Na}$ Ciência da Informação (CI) estes aspectos são fundamentais para o compartilhamento e a apropriação do conhecimento, outorgando a estes profissionais a competência de gerir os fenômenos relacionados à Gestão da Informação (GI) e da Gestão do Conhecimento (GC).

A gestão documental se integra como atividade de GI e seu enfoque está nos fluxos formais do ambiente organizacional e nos documentos de informação arquivística, seja ela orgânica e não orgânica (VALENTIM, 2012). Os documentos de arquivos gerados na administração pública ou privada, cumprem a sua função orgânica que vai da sua origem administrativa à histórica, fortalecendo os laços entre os arquivos e as suas funções sociais. Nesse sentido, são concebidos como "elo com um passado de continuidade e de 
descontinuidade, que leva a aclarar suas dimensões sociais e suas contribuições diretas na organização da sociedade de informação" (BARROS; AMÉLIA, 2009, p. 56).

Os arquivos administrativos tidos como "Arquivo com predominância de documentos decorrentes do exercício de atividades meio de uma instituição" (Aplicação da técnica de eye tracking em pesquisas envolvendo a tomada de decisão ARQUIVO NACIONAL, 2001, p. 135.), percorrem seu ciclo vital como documentos que subsidiaram diferentes fatos e tomadas de decisão nas organizações, possuem características heterogêneas e estão dispersos nas mais variadas categorias, sendo também representantes da memória da organização.

Atualmente, a GI e a GC são apoiadas pelos fluxos informacionais formais e informais. O conhecimento explícito está inserido nos fluxos formais da informação sendo objeto da GI, enquanto o conhecimento tático, objeto da GC, está nos fluxos informais ou nos ativos intelectuais, ambos em atividades organizacionais que se complementam em evidente vínculo para a gestão da Memória Organizacional (VALENTIM, 2012).

Considerando a GI e a GC como fenômenos que se completam, compreende-se que os fluxos informacionais informais detêm os ativos intelectuais da organização e estes compõem o acervo do conhecimento tácito. Evidente que estes ativos são identificados nas fontes documentais orais, as quais constituem o principal insumo para a GC na organização, enquanto a conversão do conhecimento tácito em explícito representa o cerne da Memória Organizacional (MO).

Considerando a gestão da memória como fonte de recuperação da informação das fontes informais do conhecimento tácito, esta pesquisa de caráter qualitativo, exploratório e descritivo teve por objetivo identificar como as fontes orais podem preencher as lacunas documentais no âmbito das organizações através das narrativas de memória. Nesta perspectiva, buscou-se desenvolver uma discussão com teóricos da área da Ciência da Informação e suas principais abordagens sobre as conexões existentes entre a GI, a GC e a relevância documental das fontes orais para a gestão de memória. 


\section{Fontes orais da informação e o conhecimento tácito}

A valorização da oralidade remonta a antiguidade, muito antes da invenção da escrita, surge como prática de comunicação mantida de geração a geração e reproduzida pela memória para o desenvolvimento histórico-social da humanidade (BARBOSA, 2013; VIEIRA, 2014).

$\mathrm{Na}$ arquivologia, as fontes orais são constituídas pelos acervos das entrevistas de história oral que são armazenadas em mídias audiovisuais a partir das narrativas das experiências dos entrevistados. Geralmente se relacionam aos conceitos de história oral como metodologia de caráter interdisciplinar que pode ser definida como:

Fontes para o estudo da história contemporânea surgida em meados do século XX, após a invenção do gravador a fita. Ela consiste na realização de entrevistas gravadas com indivíduos que participaram de, ou testemunharam, acontecimentos e conjunturas do passado e do presente (ALBERTI, 2010, p. 156).

Quanto ao registro das fontes orais, a autora supra entende que estas fontes são testemunhos que por excelência precisam de tratamento, no que tange ao seu registro e difusão, visto que ampliam conhecimentos sobre experiências e práticas. Preocupação dividida por Montysuma e Moser (2016) sobre a segurança do suporte dos acervos das fontes orais, indicando que por mais desafiador que seja, o ideal seria manter o acervo armazenado em diferentes tipos de mídias.

No âmbito da CI, as fontes orais possuem caráter interdisciplinar, direcionados a comunicação da informação em um sentido mais amplo, como "formas de expressão oral fundamentais nas relações humanas e imprescindível no desenvolvimento de pesquisas nos espaços de informação, cultura e leitura” (BORTOLIN; ALMEIDA JÚNIOR, 2015).

Brusamolin e Suaiden (2014), como pesquisadores da CI, descrevem que um dos maiores desafios para os profissionais da área, no âmbito organizacional, está na inserção das fontes orais ou narrativas no ciclo informacional, o que tem provocado pesquisas voltadas para as narrativas da memória no contexto da GI e da GC.

Nessa perspectiva, os autores observam que ainda existem barreiras voltadas para os antigos paradigmas de vincular a oralidade como uma forma de comunicação, ao invés de reconhecê-la como uma fonte de informação. (BRUSAMOLIN; SUAIDEN, 2014).

Valentim (2008) explica que existem diferenças consubstanciais entre os fluxos informacionais no processo da GI e da GC. As atividades básicas e demandas na GI estão na 
identificação da informação enquanto na GC estão em identificar o conhecimento. Da mesma forma, a autora demonstra implícita uma relação convergente entre o conhecimento tácito e explícito, fatores que são determinantes para a socialização e compartilhamento do conhecimento organizacional (Figura 1).

Figura 1 - Comparação entre os fluxos informacionais na GI e GC

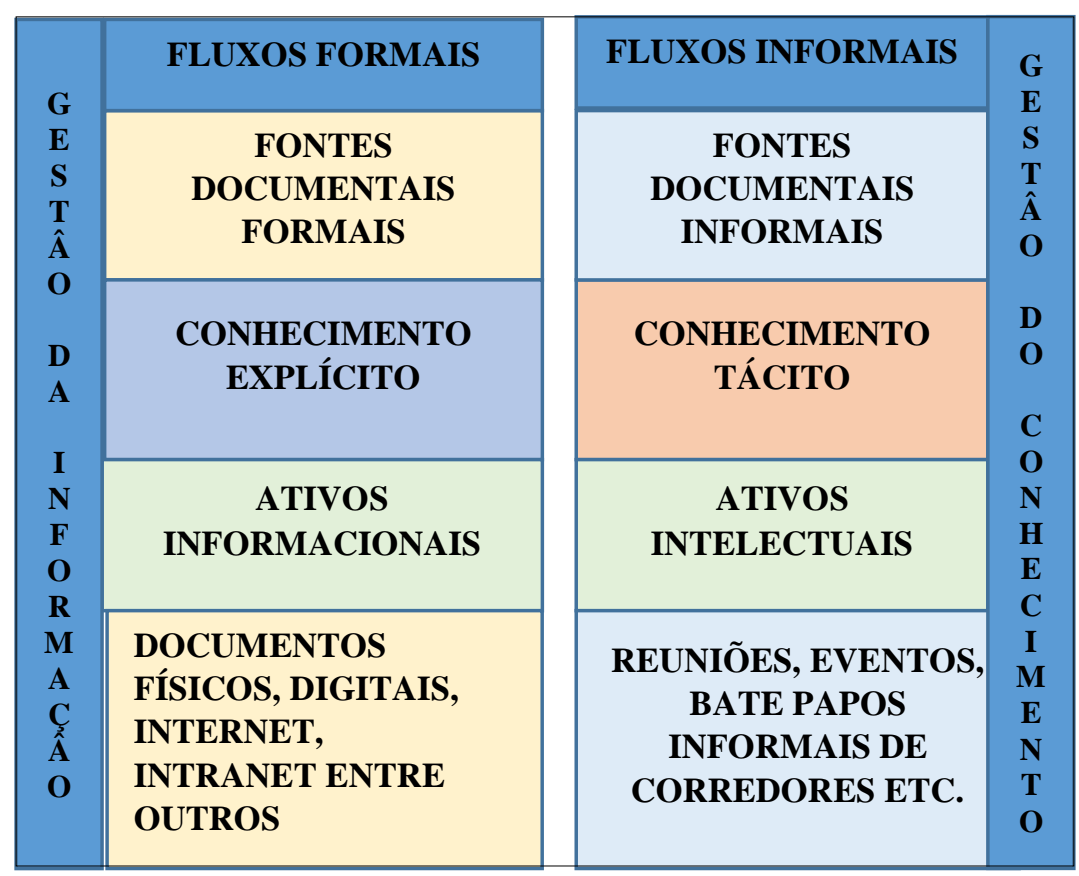

Fonte: adaptado de Valentim (2008, p. 31)

Nesta pesquisa, as fontes orais são percebidas como fontes de informação representativas da explicitação do conhecimento tácito para fins da GI e da GC. Estas fontes, quando passam pelo processo de conversão do conhecimento tácito para o explícito, transformam-se em fontes formais de informação para a organização.

Baseado nos tipos dos conhecimentos organizacionais, os autores Nonaka e Takeuchi (1997) desenvolveram a teoria da criação do conhecimento organizacional fundamentado em dois tipos de conhecimento: conhecimento tácito e explícito. Considerando ainda o modo como esses conhecimentos podem ser convertidos, os autores explicam que o conhecimento tácito é altamente pessoal e difícil de formalizar, e está enraizado nas ações e experiências, emoções, valores ou ideais do indivíduo, como os insights e palpites subjetivos que se incluem nessa categoria de conhecimento. (NONAKA; TAKEUCHI, 1997).

Os autores, ao abordarem o conhecimento explícito, explicam que este pode ser expresso em palavras e números, e facilmente comunicado e compartilhado sob a forma de 
dados brutos, fórmulas científicas, procedimentos codificados e facilmente processados por um computador, transmitido eletronicamente ou armazenado em banco de dados (NONAKA; TAKEUCHI, 1997).

Observa-se que a informação e o conhecimento constituem o núcleo central do conhecimento organizacional e ao seu desenvolvimento, enquanto as fontes orais da informação preenchem as lacunas representadas pelos ativos intangíveis ou intelectuais, contribuindo para a geração de ativos tangíveis ou documentais, como principal fator para o desenvolvimento do conhecimento organizacional.

\subsection{Gestão de memória}

A memória emerge no novo cenário social em que o maior desafio para as organizações está em desenvolver habilidades de aprender e armazenar o conhecimento como produto da memória individual e coletiva das pessoas. Construída a partir das experiências adquiridas e apropriadas como conhecimento tácito, a memória organizacional é utilizada para fins de GC.

A gestão da memória se situa intimamente com os estudos da GI e da GC, principalmente como diálogo interdisciplinar sobre políticas de informação, documentação e de comunicação no contexto das organizações na sociedade contemporânea.

A aproximação da gestão da memória com a arquivística está nas possibilidades de materialização da memória onde "[...] estariam as pesquisas ligadas à memória social, aquela que se constrói socialmente e que pode ser percebida e estudada por meio dos registros informacionais" (OLIVEIRA; RODRIGUES; CASTRO, 2017, p. 5).

Na perspectiva da GI e da GC nas organizações, Oliveira (2014) entende a memória como um ativo intangível, que aliado a GC, constitui ferramenta para inovação e renovação de conhecimento, quiçá novos conhecimentos. Nesse sentido, a autora imputa à memória a função complementar de preservação do conhecimento:

A partir do momento que a empresa possibilita processos que envolvem memória e gestão do conhecimento, se dissemina e se preserva recursos de conhecimento, otimizando esforços que tornam as práticas mais dinâmicas, impedindo retrabalhos (OLIVEIRA, 2014, p. 261, grifo nosso).

Ainda nos termos da GI, Oliveira, Rodrigues e Castro (2017) argumentam que a representatividade da memória está na sua exteriorização, nos processos informacionais de 
organização e recuperação da informação. Elemento cognitivo destes processos, a memória se apresenta como tema relevante para a CI nas pesquisas atuais, seja por seu caráter de recuperação e reutilização da informação ou como parâmetros de aprendizagem e construção de novos conhecimentos.

Diferentes enfoques são atribuídos à memória quando contextualizada no âmbito organizacional, evolução que não foge aos novos paradigmas da CI que tem seu valor atribuído as suas conexões individuais e sociais com o sujeito (CAPURRO, 2003).

A gestão de memória já está instituída como linha de estudo em vários programas de pós-graduação de universidades do Brasil. Nesse sentido, buscou-se identificar as principais pesquisas desenvolvidas nos últimos cinco anos sobre a MO contextualizada na GI e na GC.

Através de dados coletados do Sistema de Informação de Teses e Dissertações da Biblioteca Digital Brasileira de Teses e Dissertações (BDTD), buscou-se apresentar as pesquisas de Pós-Graduação mais recentes, desenvolvidas no contexto da memória, informação e conhecimento, como elementos da GI, GC e MO, para justificar como as temáticas se relacionam no campo da CI e da sua interdisciplinaridade.

Com base nas pesquisas desenvolvidas pelos Programas de Pós-Graduação (Quadro 1) entende-se que a gestão da memória tem sido explorada na estruturação da MO como repositório detentor do conhecimento organizacional, por meio das práticas da GI e da GC. Dessa maneira, explorar a MO se torna um desafio que instiga principalmente os profissionais da informação, por contemplarem os novos significados no campo de atuação em que, a informação, memória e conhecimento possuem papel central e protagonizam os discursos da aprendizagem e do conhecimento organizacional. 
Quadro 1 - Recorte de pesquisas relevantes no Brasil: MO no contexto da GI e GC

\begin{tabular}{|c|c|c|c|c|}
\hline Data & Autor & Título & Universidade & Área \\
\hline 2016 & $\begin{array}{l}\text { BARBOSA, Érica } \\
\text { Dalloz Eller }\end{array}$ & $\begin{array}{l}\text { Os impactos da } \\
\text { terceirização de serviços de } \\
\text { tecnologia de informação } \\
\text { na memória organizacional } \\
\text { de instituições de ensino } \\
\text { superior }\end{array}$ & $\begin{array}{l}\text { Universidade } \\
\text { Presbiteriana } \\
\text { Mackenzie }\end{array}$ & $\begin{array}{c}\text { Mestrado em } \\
\text { Administração de } \\
\text { Empresas }\end{array}$ \\
\hline 2016 & $\begin{array}{l}\text { LOUREIRO, } \\
\text { Érica de Castro }\end{array}$ & $\begin{array}{l}\text { Conhecimento e memória } \\
\text { na Casa de Oswaldo } \\
\text { Cruz/Fiocruz: reflexões e } \\
\text { elementos para a } \\
\text { construção de iniciativas } \\
\text { de memória organizacional }\end{array}$ & UFRJ & $\begin{array}{l}\text { Mestrado em } \\
\text { Ciência da } \\
\text { Informação }\end{array}$ \\
\hline 2017 & $\begin{array}{l}\text { GUTIERREZ, } \\
\text { Ana Lérida } \\
\text { Pacheco }\end{array}$ & $\begin{array}{l}\text { Memória institucional e } \\
\text { gestão documental no } \\
\text { Instituto de Matemática e } \\
\text { Estatística da UFRGS }\end{array}$ & $\begin{array}{c}\text { Universidade La } \\
\text { Salle }\end{array}$ & $\begin{array}{l}\text { Mestrado em } \\
\text { Memória Social e } \\
\text { Bens Culturais }\end{array}$ \\
\hline 2018 & $\begin{array}{l}\text { BEUX, Cláudia } \\
\text { Freire }\end{array}$ & $\begin{array}{l}\text { A memória organizacional } \\
\text { no Relatório de Gestão da } \\
\text { Universidade Federal do } \\
\text { Rio Grande do Sul no } \\
\text { período de } 2008 \text { a } 2016 .\end{array}$ & $\begin{array}{l}\text { Universidade } \\
\text { LASALLE }\end{array}$ & $\begin{array}{c}\text { Mestrado } \\
\text { Profissional em } \\
\text { Memória Social e } \\
\text { Bens Culturais }\end{array}$ \\
\hline 2018 & $\begin{array}{c}\text { JUSTO, Rebeca } \\
\text { Gutierres } \\
\text { Boughostan }\end{array}$ & $\begin{array}{l}\text { Relações entre o ciclo de } \\
\text { inteligência competitiva e } \\
\text { as funções da memória } \\
\text { organizacional: estudo } \\
\text { com foco na concorrência }\end{array}$ & $\begin{array}{l}\text { Universidade } \\
\text { Presbiteriana } \\
\text { Mackenzie }\end{array}$ & $\begin{array}{c}\text { Mestrado em } \\
\text { Administração de } \\
\text { Empresas }\end{array}$ \\
\hline 2019 & $\begin{array}{c}\text { CORTES, } \\
\text { Vanderléa } \\
\text { Nóbrega Azevedo }\end{array}$ & $\begin{array}{l}\text { Estruturação da Memória } \\
\text { Organizacional por meio } \\
\text { da } \\
\text { Gestão do Conhecimento: } \\
\text { entre o tácito e o explícito. }\end{array}$ & UFS & $\begin{array}{c}\text { Mestrado } \\
\text { Profissional em } \\
\text { Gestão da } \\
\text { Informação e do } \\
\text { Conhecimento. } \\
\end{array}$ \\
\hline 2019 & $\begin{array}{c}\text { FEITOZA, Rayan } \\
\text { Aramís de Brito }\end{array}$ & $\begin{array}{c}\text { Memória organizacional } \\
\text { no contexto dos processos } \\
\text { de gestão do conhecimento } \\
\text { associados às práticas } \\
\text { arquivísticas } \\
\end{array}$ & UFPB & $\begin{array}{l}\text { Mestrado em } \\
\text { Ciência da } \\
\text { Informação }\end{array}$ \\
\hline 2019 & $\begin{array}{l}\text { SANTOS, Juliana } \\
\text { Cardoso dos }\end{array}$ & $\begin{array}{l}\text { Memória organizacional: } \\
\text { em foco o valor da } \\
\text { informação como } \\
\text { negócio/commodity }\end{array}$ & UNESP/Marília & $\begin{array}{l}\text { Doutorado em } \\
\text { Ciência da } \\
\text { Informação }\end{array}$ \\
\hline 2020 & $\begin{array}{c}\text { CÂNDIDO, } \\
\text { Gilberto Gomes }\end{array}$ & $\begin{array}{l}\text { O ato narrativo e a ética na } \\
\text { descrição do documento de } \\
\text { arquivo. }\end{array}$ & UNESP/Marília & $\begin{array}{l}\text { Doutorado em } \\
\text { Ciência da } \\
\text { Informação } \\
\end{array}$ \\
\hline 2020 & $\begin{array}{l}\text { CARMO, Monica } \\
\text { Elisque do }\end{array}$ & $\begin{array}{l}\text { Gestão e organização da } \\
\text { memória organizacional: } \\
\text { geoparque quadrilátero } \\
\text { ferrífero em Minas Gerais }\end{array}$ & UFMG & $\begin{array}{l}\text { Doutorado em } \\
\quad \text { Gestão e } \\
\text { Organização do } \\
\text { Conhecimento } \\
\end{array}$ \\
\hline
\end{tabular}

Fonte: elaborado pelas autoras com base nos dados da pesquisa (2020)

Evidencia-se que conceito de Memória Organizacional transita entre a conservação, retenção e a reestruturação no âmbito das vivências e práticas cotidianas das pessoas que 
compõem a organização. No campo organizacional, a gestão de memória se constitui nas diferentes formas de recuperação e ressignificação da informação, ou seja, distinguir o que pode e deve ser recuperado para fins de gestão (ALMEIDA, 2017).

Entende-se que gestão da memória consiste em identificar qual conhecimento é plausível de armazenamento do ponto de vista da atividade organizacional. Para Huyssen (2000), a memória resulta das experiências e percepções do homem, sempre vulneráveis às mudanças históricas e sociais. Thiesen (2013) atribui a este caráter dinâmico da memória a sua subjetividade presente nas experiências discursivas, a qual, no contexto institucional "é uma construção social e não um reservatório de dados. Portanto, jamais pode ser resgatada, mas sim reconstruída” (THIESEN, 2013, p. 33).

Explicar a gestão da memória não se resume a uma temática fácil, pois está sedimentada nas fronteiras interdisciplinares do saber, o que instiga as pesquisas que buscam explicar desde a sua conceituação até a sua construção como processo de manutenção do conhecimento.

\subsection{Narrativas de memória na organização}

As definições sobre narrativas são atribuídas às narrativas de histórias, história oral, narrativas de memória, Storytelling ou simplesmente narrativas, que reproduzem os relatos orais baseados em experiências, as quais possibilitam um conhecimento específico que se renova a cada experiência de recordar (BRUSAMOIN; SUAIDEN, 2014; RIBEIRO, 2016).

Trata-se de uma prática cultural milenar que, potencializada pelas novas formas de comunicação advindas das mídias tecnológicas, tem sido reconhecida na sociedade atual como ferramenta de comunicação e interação humana e como práticas de gestão, de marketing e business nas empresas (SANTOS; MORO-CABERO; VALENTIM, 2016).

A virada das narrativas nas ciências sociais coincide com a explosão da internet e com os avanços tecnológicos inerentes à década de noventa que potencializaram as condições do Storytelling (SALMON, 2016). Retomada esta, que encontrou lugar no mundo dos negócios e como metodologia de comunicação da narrativa de memória, alcançando os limites da cientificidade, identificada por Cogo (2016, p. 95, grifo nosso) como um possível novo paradigma, a saber: "o paradigma narrativo". 
Nas organizações atuais, as narrativas promovem o protagonismo dos indivíduos possibilitando identificar o conhecimento tácito adquirido ao longo do tempo, atuando como forma de transmissão da oralidade coletiva e de socialização do conhecimento (SANTOS; MORO-CABERO; VALENTIM, 2016).

Tarapanoff (2006, p.14) recorre às narrativas de memória como estratégia para a GC, no sentido em que servem de registro para compor a história da organização, alimentar a GC em repositórios de $\mathrm{MO}$ e contribuir para os processos de inovação e compartilhamento do conhecimento.

No campo da comunicação empresarial, as narrativas de memória estão relacionadas com os relatos da trajetória institucional, sua estrutura, corpo funcional, sua missão, função social, refletindo como ela está no presente, valorizando todos os passos percorridos junto à sociedade. Nassar (2007) enfatiza a importância de memória como fonte de patrimônio do conhecimento para a organização, apoio estratégico e elemento de responsabilidade social e histórica. Enquanto Worcman (2004), complementa que as narrativas possibilitam a sistematização da memória pela preservação do conhecimento intangível, atuando como marco referencial de novos significados aos valores e experiências profissionais.

Cogo (2016) vislumbra uma relação direta entre memória, experiências e narrativas plurais que proporcionam e que representam para a organização a subjetividade do seu passado, reafirmam o seu presente e influenciam o seu futuro, descrevendo a memória como "contribuinte efetiva do enfoque das interações informativas e relacionais, sobre maneira de valoração de ativos intangíveis" (COGO, 2016, p. 71).

Identifica-se ainda, o paradigma narrativo para a comunicação organizacional e o resgate da memória pela oralidade, no qual lacunas documentais e históricas são preenchidas. Sob essa ótica, Cortes (2017) realizou uma pesquisa de abordagem prática sobre a informação documental e narrativas orais como possibilidade de estruturação da MO. A autora observou que no contexto da GI existem perdas documentais irreparáveis no tocante à memória organizacional, em que o verdadeiro resgate documental está na "cumplicidade do arquivo, no garimpo dos documentos setoriais guardados como troféus ou mesmo no silêncio das custódias particulares e na oralidade de um grupo" (CORTES, 2017, p. 6).

Observando ainda que o conhecimento tácito seria mais complexo e de difícil apreensão, Cortes (2019) desenvolveu pesquisa sobre a estruturação da Memória Organizacional por meio 
da GC aplicando a metodologia do Storytelling. Para a autora, a metodologia do Storytelling é composta inicialmente por um indutor que provoque a ação da narrativa, podendo ser uma palavra, um conto, um texto, uma música, uma imagem e tantas outras opções, em que se construa um contexto de significados para os entrevistados e, esbarra em barreiras de um denominador comum chamado tempo e a sucessão de várias gestões, que nem sempre estão prontas para entender os momentos sociais anteriores.

Cortes (2019) evidenciou que as narrativas de Storytelling são uma metodologia que transpõe as barreiras da exteriorização do conhecimento tácito porque o identifica através dos relatos das práticas da GC e possibilita a sua formalização por meio da GI, ambas objeto de estudo da CI. A autora discute ainda que a institucionalização da gestão da memória em um espaço corporativo é influenciada pela cultura organizacional interferindo diretamente em suas ações, podendo desta forma enfraquecer ou fortalecer a sua gestão.

A narrativa de memória nas organizações vem contribuir, enfim, como processo metodológico de estruturação da memória com base nas ações da conversão do conhecimento tácito em explícito pelas práticas da GC.

\section{Metodologia}

Desenvolvida por meio de procedimentos técnicos caracterizados como estudo de revisão narrativa de literatura, este estudo buscou identificar as principais pesquisas desenvolvidas por autores clássicos e contemporâneos, a evolução sobre a temática e como esta tem evoluído no campo científico, possibilitando apresentar “ publicações amplas, apropriadas para descrever e discutir o desenvolvimento do "estado da arte" de um determinado assunto, sob o ponto de vista teórico ou contextual" (ROTHER, 2007, p.125).

Partindo deste princípio, foi realizada uma pesquisa em fontes digitais científicas na área da Ciência da Informação, para configuração do estado da arte, e construção do referencial teórico. Por meio da revisão narrativa de literatura, conceitos e juízos foram levantados, utilizando-se a busca temática em bases de dados científicas, repositórios digitais, em catálogos de acervos físicos e digitais, descritas pelos termos: Fontes Orais, Memória, Memória Organizacional, Gestão da Informação, Gestão do Conhecimento e Fluxos Informacionais. 
Estabeleceu-se como recorte temporal o período máximo de cinco anos, para as publicações de artigos, teses e dissertações, contudo, a data de publicação dos livros pesquisados foi flexibilizada, por se tratar de obras, em sua maioria, de referência para a área. Não foi direcionada a nenhuma entidade específica, mas, buscou-se identificar a relevância documental das fontes orais para as narrativas da memória nas organizações através dos aportes teóricos. A metodologia da pesquisa foi de cunho qualitativo e interpretativo, sendo sua natureza básica e de alcance exploratório.

Utilizou-se os descritores nas plataformas de busca e operadores booleanos para refinamento da busca e melhor fundamentação sobre o tema, demonstrado no quadro elaborado pelas autoras (Figura 2).

Figura 2 - Principais termos de busca e refinamento da pesquisa

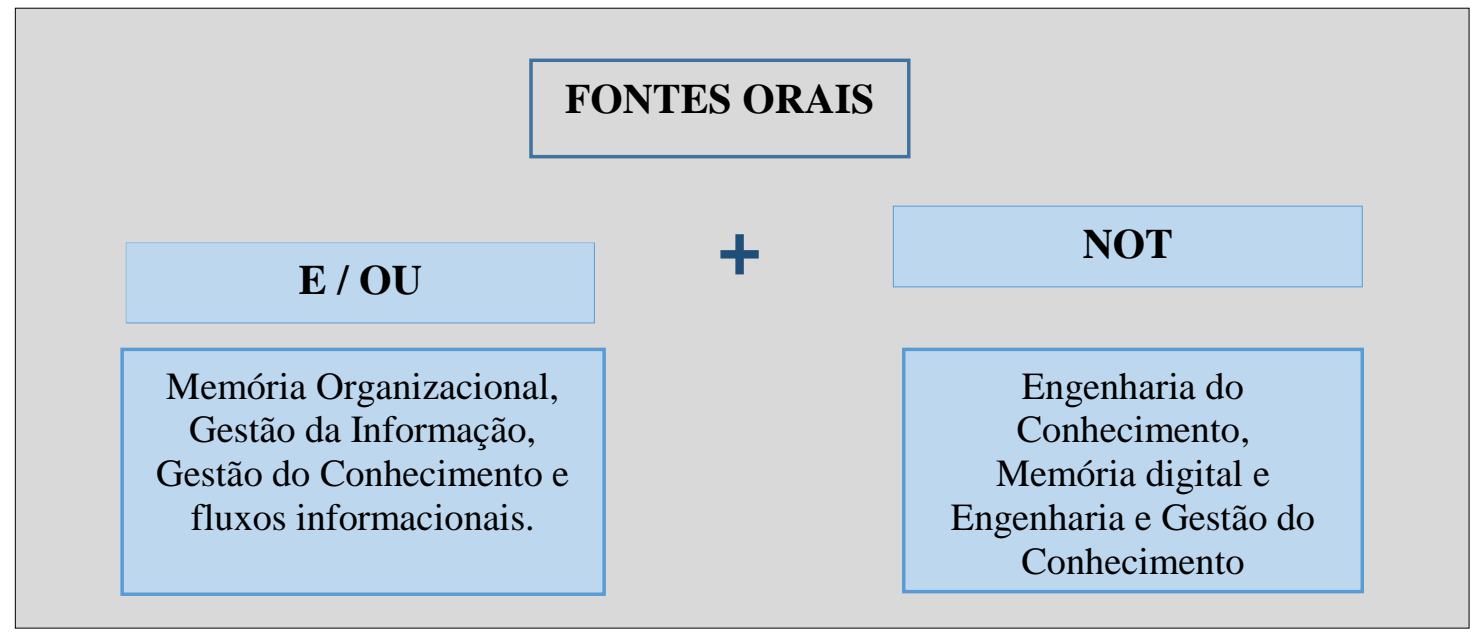

Fonte: elaborado pelas autoras (2020).

Nessa perspectiva, a revisão narrativa possibilitou "a compreensão do movimento da área, sua configuração, propensões teóricas, metodológicas, análise crítica indicando tendências, recorrências e lacunas" (VOSGERAU; ROMANOWSKI, 2014, p. 167) embasando as discussões a serem analisadas na próxima seção. 


\section{Resultados e Discussões}

As pesquisas sobre as fontes orais no âmbito da Ciência da Informação representam a formalização dos fluxos informais ou da informação de conhecimento tácito, por isso ocupa uma área muito mais abrangente que a própria arquivologia. Contudo, são relações indissociáveis, à medida que, sua organização e tratamento possibilitam a recuperação para fins de gestão. Nesse sentido, Cogo (2016) entende que pode estar ocorrendo o novo "paradigma narrativo" porque o conhecimento tácito ou intangível está dentro das pessoas e no âmbito organizacional a sua recuperação deve e pode ser realizadas por meio de metodologias que possam recuperar o conhecimento tácito e gerir o conhecimento organizacional. Entende-se, que para fins de lacunas documentais, muitas vezes irrecuperáveis em termos materiais, evocar a narrativa se torna a única possibilidade e esta preocupação está tangente no fazer profissional dos profissionais da informação.

Ao analisarmos o papel das narrativas na atualidade, autores como Brusamolin e Suaiden (2014), Cogo (2016) e Salmon (2016), se destacam entre tantos outros que entendem a narrativa como possibilidade nas metodologias de comunicação e de Ciência da Informação, para gerir o conhecimento tácito, principalmente, fortalecidas tecnologias digitais e pelo uso estratégico do capital intelectual e aprendizagem organizacional para o crescimento corportativo das organizações.

As narrativas de memória possibilitam estruturar a Memória Organizacional por meio dos fluxos documentais informais formalizando estes para composição dos fluxos formais, neste contexto pudemos identificar que a memória constiuti aspectos de inteligencia organzacional, processos, recuperação, preservação e utilização da informação para fins estratégicos, justificativa explorada durante a pesquisa por autores como Nassar (2007) e Worcman (2004) no que evocam a meméria como uma história a ser pensada além de um resgate, entendem que seja um marco referencial para identificar experiências e valores que possam reforçar novas experiências ou evitar repetição de errros cometidos ao longo do tempo. Em tempo real, a memória é o presente que nunca deixou de existir, cabe a gestão da memória, recuperar ou estruturar o que está implicito ou contido no silêncios das falas dando protagonismo aos sujeitos organizacionais.

Discutiu-se, por fim, a gestão da memória nas organizações, trazendo no quadro 1 um recorte de pesquisas relevantes no Brasil que abordam a Memória Organizacional no contexto 
da Gestão da Informação e do Conhecimento. Buscou-se apresentar neste recorte algumas pesquisas de Pós-Graduação mais recentes, desenvolvidas no contexto da memória, informação e conhecimento, como elementos da GI, GC e MO, para justificar como as temáticas se relacionam no campo da $\mathrm{CI}$ e da sua interdisciplinaridade.

Estudo a respeito do conceito de memória e sua abordagem segundo a perspectiva da Gestão do Conhecimento (GC) são desenvolvidas em áreas interdisciplinares com pesquisas voltadas para estruturar, recuperar e formalizar o conhecimento organizacional. Estabelecer iniciativas e metodologias de narrativas de memórias tem sido uma preocupação para formalização do conhecimento. Barbosa (2016), Loureiro (2016) e Beux (2018) apontam em suas pesquisas reflexões sobre temas correlatos ao conceito de memória e a Gestão Documental (GD), com ênfase em narrativas, esquecimento, temporalidade, memoria social e coletiva, documentos e arquivos, fontes documentais orais além das suas relações interdisciplinares.

Correlações entre o ciclo de inteligência competitiva e as funções da Memória Organizacional (MO) voltada para a gestão do conhecimento e tomada de decisão, concorrência, inteligência organizacional entre outros, tem sido desenvolvida principalmente pela área da Administração, conforme discute Justo (2018), ao afirmar que existe uma preocupação atual em utilizar repositórios de retenção da MO como banco de dados de ciclos de informações de inteligências competitivas. Avançando para Carmo (2020) e Santos (2019), sob visão do valor da informação para a Ciência da Informação (CI), identificamos em seus trabalhos a importância de explicitar conhecimentos informais e superar a ênfase em artefatos. Convergem para a gestão documental da informação, oral ou escrita, com duas diferentes perspectivas: informação e conhecimento que aliados transformam a memória organizacional em um repositório de informações seletivas para tomada de decisão.

Gutierrez (2017) buscou investigação sobre as relações entre memória institucional e gestão documental no Instituto de Matemática e Estatística (IME) da Universidade Federal do Rio Grande do Sul (UFRGS) identificando que a memória é efêmera e se dilui no tempo, por isso busca a gestão documental para restabelecer laços que foram fragmentados. A autora compreende que a gestão de memória pode consolidar sua institucionalização. Concepção corroborada por Feitoza (2019) que, objetivando analisar como os processos de gestão do conhecimento associados às práticas arquivísticas podem contribuir para a preservação da memória organizacional, identificou que esta associação e as estratégias para o 
compartilhamento e criação do conhecimento na empresa podem preservar a memória organizacional, elencando as seguintes características para esse fim:

\footnotetext{
$\checkmark$ Manter uma cultura organizacional propícia e adoção da gestão do conhecimento;

$\checkmark$ Criar políticas de gestão do conhecimento e de práticas arquivísticas;

$\checkmark$ Conservar a relação estratégica entre a gestão do conhecimento alinhada ao setor de arquivo;

$\checkmark$ Possuir uma equipe integrada e interdisciplinar no setor de arquivo;

$\checkmark$ Conhecer, planejar e preservar os conhecimentos de uma organização visando sua memória organizacional (FEITOZA, 2019, p. 164).
}

Sob esta mesma perspectiva, Cortes (2019) realizou uma intervenção na Procuradoria da União no Estado de Sergipe (PU/SE/AGU) com o objetivo de estruturar a memória organizacional por meio da gestão do conhecimento utilizando uma metodologia de narrativas de memórias conhecido por Storytelling. A autora identificou que os principais protagonistas da memória são os sujeitos organizacionais que narraram suas experiências e legados, portanto, trabalhar a informação, o conhecimento e a memória, só é possível com uma intervenção por meio das narrativas como prática social da memória na organização. Apontou a necessidade da formação de um conselho paritário de gestão de memória para elaboração e implantação de políticas, normas, capacitações e discussões colegiadas sobre a memória organizacional, enquanto a organização não promove a institucionalmente a gestão de memória em seu planejamento estratégico (CORTES, 2019).

Para Cortes (2019, p. 114) uma das principais observações é que a "Memória Organizacional é acima de tudo um conjunto de práticas formalizadas da GC”, observa-se que tal compreensão remete ao fato de que diálogos existentes entre a informação, conhecimento e memória estão inseridos nas práticas organizacionais e precisam ser reconhecidos pelos profissionais da informação como forma de atuação proativa e inovadora.

Cândido (2020) deu ênfase a questão ética em sua tese de doutoramento intitulada: O ato narrativo e a ética na descrição do documento de arquivo. $\mathrm{O}$ autor destaca a preocupação com a ética na descrição das narrativas dos documentos e a estrutura da sua descrição, uma vez documentada, passará a compor a memória sob diversos aspectos da arquivista, como partícipe da memória social. Para Cândido (2020, p. 94) as narrativas possuem estruturas e características que podem ser consideradas "um tipo inerente ao cotidiano social, no qual se relatam fatos que remontam a identidade de uma determinada sociedade advindo se suas ações, aludindo às perspectivas de mundo real quanto de ficções". 


\section{Considerações finais}

A pesquisa permitiu identificar a importância das fontes orais para as narrativas de memória através de diferentes contextos organizacionais. Identificou que as fontes orais são constituídas de narrativas de memória que permitem formalizar o conhecimento tácito. Identificou-se que a subjetividade dos elementos que constituem as fontes informais ou ativos intelectuais são de difícil apreensão, porque elas estão intrínsecas no conhecimento individual das pessoas que compõem a organização.

A relevância das fontes orais está na possibilidade de identificação do conhecimento organizacional, através de metodologias que possam formalizar o conhecimento individual reflexivo e internalizado nos sujeitos organizacionais, que muitas vezes se evadem da organização levando consigo todas as práticas e experiências adquiridas em sua trajetória. Torna-se essencial que estas fontes sejam tratadas e retidas em reservatórios de conhecimento representados pela memória organizacional.

Identificou-se através dos autores da área da Ciência da Informação, que a temática está inserida nos seus debates contemporâneos, fato identificado pelas pesquisas recentes entre as fontes de informação, narrativas de memória e memória organizacional como prática de GC apresentadas no quadro 1 .

Demonstra-se a necessidade de implantação de propostas de gestão documental com foco no armazenamento e recuperação da informação, para fins de comunicação e apropriação do conhecimento organizacional, a partir dos diálogos sobre políticas de informação e gestão de memória.

Conclui-se que os arquivos administrativos conduzem o fluxo informacional formal para a GI e tomada de decisão, mas a memória está nos fluxos informais ou ativos intelectuais para a GC. Nesse sentido, a memória está reconhecida como fenômeno de estudo e apropriação da Ciência da Informação.

Enfatiza-se, enfim, a importância do protagonismo dado as fontes orais da informação, como forma de compreensão das experiências passadas de um grupo social, servindo como referência para a organização no presente e elemento norteador para o futuro. 
Conclui-se finalmente que as fontes formais e informais representam a GI e a GC, respectivamente, correspondendo a um conjunto de práticas que precedem e estruturam a memória da organização e do seu conhecimento, estando inter-relacionada com os arquivos administrativos e com a memória, contributos para ampliação da identidade e da função social da instituição.

Esta pesquisa não leva a fechar círculos, mas possibilita instigar e ampliar novos discursos que possam contribuir para a área da documentação, história, memória, GI e GC no contexto da Ciência da Informação e sua interdisciplinaridade.

\section{Referências}

ALBERTI, Verena. História dentro da História. In: PINSKY, Carla Bassanezi (org.). Fontes históricas. São Paulo: Contexto, 2010.

ALMEIDA, Maurício Barcellos. Memória organizacional: como as organizações armazenam e recuperam informações para fins de gestão. In: OLIVEIRA, Eliane Braga de;

RODRIGUES, Georgete Medleg (org.). Memória: interfaces no campo da informação. Brasília: Ed. UnB, 2017. p. 215-247.

ARQUIVO NACIONAL (Brasil). Dicionário brasileiro de terminologia arquivística. Rio de Janeiro: Arquivo Nacional, 2001. p. 135. Disponível em:

http://www.arquivonacional.gov.br/images/pdf/Dicion_Term_Arquiv.pdf. Acesso em: 12 abr. 2020.

BARBOSA, Érica Dalloz Eller. Os impactos da terceirização de serviços de tecnologia de informação na memória organizacional de instituições de ensino superior. $2016.96 \mathrm{f}$. Dissertação (Mestrado em Administração de Empresas) - Universidade Presbiteriana Mackenzie, São Paulo, 2016. Disponível em: http://tede.mackenzie.br/jspui/bitstream/tede/2846/5/Erica\%20Dalloz\%20Eller\%20Barbosa.p df. Acesso em: 20 maio 2020.

BARBOSA, Marialva Carlos Barbosa. História e memória como processo de reflexão e aprendizado. In: MARCHIORI, Marlene. História e memória (org.). Rio de Janeiro: Ed. Senac, 2013. p. 63-73.

BARROS, Dirlene Santos; AMELIA, Dulce. Arquivo e memória: uma relação indissociável. Transinformação, Campinas, v. 21, n. 1, p. 55-61, 2009. Disponível em: http://www.scielo.br/scielo.php?pid=S010337862009000100004\&script=sci_abstract\&tlng=pt. Acesso em: 12 maio 2020.

BEUX, Cláudia Freire. A memória organizacional no relatório de gestão da Universidade Federal do Rio Grande do Sul no período de 2008 a 2016. 2018. 155 f. Dissertação (Mestrado em Memória Social e Bens Culturais) - Universidade La Salle, 2018. Disponível em: https://lume.ufrgs.br/handle/10183/189614. Acesso em: 12 abr. 2020. 
BORTOLIN, Sueli.; ALMEIDA JÚNIOR, Oswaldo Francisco de. Fontes orais, Paul Otlet e os bibliotecários. In: BORTOLIN, Sueli.; SANTOS NETO, José Arlindo dos; SILVA, Rovilson José da (org.). Mediação oral da informação e da leitura. Londrina: ABECIN, 2015. p. 59-88.

BRUSAMOLIN, Valério. SUAIDEN, Emir José. Aprendizagem organizacional: o impacto das narrativas. Curitiba: Appris, 2014. 237 p.

CÂNDIDO, Gilberto Gomes. O ato narrativo e a ética na descrição do documento de arquivo. 2020. 160 f. Tese (Doutorado em Ciência da Informação) - Faculdade de Filosofia e Ciências da Universidade Estadual Paulista, Marília, 2020. Disponível em:

https://repositorio.unesp.br/bitstream/handle/11449/192628/candido_gg_dr_mar.pdf?sequenc e=3. Acesso em: 12 abr. 2020.

CAPURRO, Rafael. Epistemologia e Ciência da Informação. In: ENCONTRO NACIONAL DE PESQUISA EM CIÊNCIA DA INFORMAÇÃO, 5, 2003, Belo Horizonte. Anais [...]. Belo Horizonte: ANCIB, 2003. p. 1-21. Disponível em: http://www.capurro.de/enancib_p.htm. Acesso em: 12 jun. 2018.

CARMO, Mônica Elisque do. Gestão e organização da memória organizacional: geoparque quadrilátero ferrífero em Minas Gerais. 2020. Tese (Doutorado em Gestão e Organização do Conhecimento) - Universidade Federal de Minas Gerais, Belo Horizonte, 2020. No prelo.

COGO, Rodrigo Silveira. Storytelling: as narrativas da memória na estratégia da comunicação. São Paulo: ABERJE, 2016. 173 p.

CORTES, Vanderléa Nóbrega Azevedo. Estruturação da memória organizacional por meio da gestão do conhecimento: entre o tácito e o explícito. 2019. 160 f. Dissertação (Mestrado Profissional em Gestão da Informação e do Conhecimento) - Universidade Federal de Sergipe, São Cristóvão, 2019. Disponível em:

https://ri.ufs.br/bitstream/riufs/12338/2/VANDERLEA_NOBREGA_AZEVEDO_CORTES.p df. Acesso em: 12 maio 2020.

CORTES, Vanderléa Nóbrega Azevedo. Informação e memória organizacional: inventário do resgate das fontes documentais como ferramenta de construção da memória organizacional. In: SIMPÓSIO INTERNACIONAL DE EDUCAÇÃO E COMUNICAÇÃO, 8, 2017, Aracaju. Anais [...]. Aracaju: Universidade Tiradentes, 2017. p. 1-15. Disponível em: https://eventos.set.edu.br/simeduc/article/view/8540/2846. Acesso em: 12 abr. 2020.

FEITOZA, Rayan Aramís de Brito. Memória organizacional no contexto dos processos de gestão do conhecimento associados às práticas arquivísticas. 2019. $190 \mathrm{f}$. Dissertação (Mestrado em Ciência da Informação) - Universidade Federal da Paraíba, João Pessoa, 2019. Disponível em: https://repositorio.ufpb.br/jspui/handle/123456789/16860?locale=pt_BR. Acesso em: 14 maio 2020. 
GUTIERREZ, Ana Lérida Pacheco. Memória institucional e gestão documental no Instituto de Matemática e Estatística da UFRGS. 2017. 116 f. Dissertação (Mestrado em Memória Social e Bens Culturais) - Universidade La Salle, Canoas, 2017. Disponível em: https://lume.ufrgs.br/bitstream/handle/10183/173273/001058137.pdf?sequence=1\&isAllowed =y. Acesso em: 12 jun. 2020.

HUYSSEN, Andreas. Seduzidos pela Memória: arquitetura, monumentos, mídia. Rio de Janeiro: Aeroplano, 2000. 5-39 p.

JUSTO, Rebeca Gutierres Boughostan. Relações entre o ciclo de inteligência competitiva e as funções da memória organizacional: estudo com foco na concorrência. 2018. $139 \mathrm{f}$. Dissertação (Mestrado em Administração de Empresas) - Universidade Presbiteriana Mackenzie, São Paulo, 2018. Disponível em:

http://tede.mackenzie.br/jspui/bitstream/tede/3636/5/REBECA\%20GUTIERRES\%20B\%20J USTO.pdf. Acesso em: 12 abr. 2020

LOUREIRO, Érica de Castro. Conhecimento e memória na Casa de Oswaldo Cruz/Fiocruz: reflexões e elementos para a construção de iniciativas de memória organizacional. 2016, 190 f. Dissertação (Mestrado em Ciência da Informação) - Escola de Comunicação, Universidade Federal do Rio de Janeiro, 2016. Disponível em:

https://www.arca.fiocruz.br/bitstream/icict/18457/2/Dissertacao_Erica_Loureiro_Ibict_2016.p df. Acesso em: 22 maio 2020.

MONTYSUMA, Marcos Fábio Freire; MOSER, Gisele Palma. História oral e arquivologia: reflexões sobre o processo de ensino-aprendizagem da metodologia da história oral e o acervo de fontes orais. In: ENCONTRO NACIONAL DE HISTÓRIA ORAL, 13, 2016, Porto Alegre. Anais [...]. Porto Alegre: [s. l.], 2016. Disponível em:

https://www.encontro2016.historiaoral.org.br/resources/anais/13/1461876674_ARQUIVO_E ncontroNacionaldeHistoriaOral-2016-artigocompleto-FINAL.pdf. Acesso em: 20 maio 2020.

NASSAR, Paulo. Relações públicas na construção da responsabilidade histórica e no resgate da memória institucional das organizações. São Caetano do Sul: Difusão, 2007. $206 \mathrm{p}$.

NONAKA, Ikujiro; TAKEUCHI, Hirotaka. Criação de conhecimento na empresa. Rio de Janeiro: Elsevier, 1997.

OLIVEIRA; Eliane Braga de; RODRIGUES, Georgete Medleg; CASTRO, Raíssa Mota. A memória na Ciência da Informação: uma análise da produção científica brasileira. In:

OLIVEIRA, Eliane Braga de; RODRIGUES, Georgete Medleg. (Org.). Memória: interfaces no campo da informação. Brasília: Ed. UNB, 2017. p. 79 - 108.

OLIVEIRA, Simone Rosa de. Memória institucional: lugar de (re)construção de uma Memória coletiva? In: SOUTO, Leonardo Fernandes (org.). Gestão da informação e do conhecimento: práticas e reflexões. Rio de Janeiro: Interciência, 2014. p. 261.

RIBEIRO, Suzana Lopes Salgado. Apresentação: dossiê "história oral e memória". Revista Outras Fronteiras, Cuiabá, v. 3, n. 1, jan./jun., 2016. Disponível em: http://ppghis.com/outrasfronteiras/index.php/outrasfronteiras/article/view/235/pdf. Acesso: maio 2020. 
ROTHER, Edna Terezinha. Revisão sistemática X revisão narrativa. Acta paul. Enferm, São Paulo, v. 20, n. 2, abr./jun. 2007. Disponível em:

https://www.scielo.br/scielo.php?script=sci_arttext\&pid=S0103-21002007000200001. Acesso em: 20 maio 2020.

SALMON, Christian. Um machine à fabriquer des thistories. Le Monde Diplomatique, Paris, nov. 2006, p. 18-19. Disponível em: http://www.sietmanagement.fr/wpcontent/uploads/2016/04/une machine_a_fabriquer_des_histoires.pdf. Acesso em: 12 abr. 2020 .

SANTOS, Juliana Cardoso dos. Memória organizacional: em foco o valor da informação como negócio/commodity. 2019. 223 f. Tese (Doutorado em Ciência da Informação) Faculdade de Filosofia e Ciências, Universidade Estadual Paulista, Marília, 2019. Disponível em:

https://repositorio.unesp.br/bitstream/handle/11449/183566/santos_jc_dr_mar.pdf?sequence= 3\&isAllowed=y. Acesso em: 23 abr. 2020.

SANTOS, Juliana Cardoso dos; MORO-CABERO, Maria Manuela; VALENTIM, Marta Lígia Pomim Valentim. A memória organizacional como diferencial competitivo em ambiente organizacional. In: SEMINÁRIO DE PESQUISA EM CIÊNCIAS HUMANAS, 11, 2016.

Anais [...]. Londrina: [s. l.], 2016. Disponível em: http://pdf.blucher.com.br.s3-sa-east1.amazonaws.com/socialsciencesproceedings/xi-sepech/gt13_89.pdf. Acesso em: 12 abr. 2020.

TARAPANOFF, Kira (org.). Inteligência, informação e conhecimento. Brasília: IBICT: UNESCO, 2006. 453 p.

THIESEN, Icléia. Memória institucional. João Pessoa: Ed. da UFPB, 2013. 312 p.

VALENTIM, Marta Lígia Pomim. Gestão documental em ambientes empresariais. In: VALENTIM, Marta Lígia Pomim (org.). Estudos avançados em arquivologia. São Paulo: Cultura acadêmica, 2012. p. 11-25.

VALENTIM, Marta Ligia Pomim. Informação e conhecimento em organizações complexas. In: VALENTIM, Marta (org.). Gestão da informação e do conhecimento. São Paulo: Polis: Cultura Acadêmica, 2008. p. 11-25.

VIEIRA, Ronaldo. Introdução à teoria geral da Biblioteconomia. Rio de Janeiro: Interciência, 2014. 330 p.

VOSGERAU, Dilmeira Sant'Anna Ramos; ROMANOWSKI, Joana Paulin. Estudos de revisão: implicações conceituais e metodológicas. Rev. Diálogo Educ., Curitiba, v. 14, n. 41, p. 165-189, jan./abr. 2014. Disponível em:

http://www2.pucpr.br/reol/pb/index.php/dialogo?dd1=12623\&dd99=view\&dd98=pb. Acesso em: 04 maio 2020.

WORCMAN, Karen. Memória do futuro: um desafio. In: NASSAR, Paulo (org.). Memória de empresa: história e comunicação de mãos dadas, a construir o futuro das organizações. São Paulo: Aberje, 2004. p. 23-30. 